\title{
Understanding the differences between contrasting HIV epidemics in east and west Africa: results from a simulation model of the Four Cities Study
}

\author{
Kate K Orroth, Esther E Freeman, Roel Bakker, Anne Buvé, Judith R Glynn, Marie-Claude Boily, \\ Richard G White, J Dik F Habbema, Richard J Hayes
}

Sex Transm Infect 2007;83(Suppl I):i5-i16. doi: 10.1136/sti.2006.023531

See end of article for authors' affiliations

Correspondence to: Dr Kate K Orroth, Infectious Disease Epidemiology Unit, London School of Hygiene and Tropical Medicine, Keppel Street, London WCIE 7HT, UK; kate. orroth@gmail.com

Accepted 18 March 2007 Published Online First 3 April 2007

\begin{abstract}
Objective: To determine if the differences in risk behaviours, the proportions of males circumcised and prevalences of sexually transmitted infections (STIs) observed in two African cities with low prevalence of HIV (Cotonou, Benin, and Yaoundé, Cameroon) and two cities with high prevalence (Kisumu, Kenya, and Ndola, Zambia) could explain the contrasting HIV epidemics in the four cities.

Methods: An individual-based stochastic model, STDSIM, was fitted to the demographic, behavioural and epidemiological characteristics of the four urban study populations based on data from the Four Cities Study and other relevant sources. Model parameters pertaining to STI and HIV natural history and transmission were held constant across the four populations. The probabilities of HIV, syphilis and chancroid acquisition were assumed to be doubled among uncircumcised males. A priori plausible ranges for model inputs and outputs were defined and sexual behaviour characteristics, including those pertaining to commercial sex workers (CSWs) and their clients, which were allowed to vary across the sites, were identified based on comparisons of the empirical data from the four sites. The proportions of males circumcised in the model, $100 \%$ in Cotonou and Yaoundé, $25 \%$ in Kisumu and 10\% in Ndola, were similar to those observed. A sensitivity analysis was conducted to assess how changes in critical parameters may affect the model fit. Results: Population characteristics observed from the study that were replicated in the model included younger ages at sexual debut and marriage in east Africa compared with west Africa and higher numbers of casual partners in the past 12 months in Yaounde than in the other three sites. The patterns in prevalence of STIs in females in the general population and CSWs were well fitted. HIV prevalence by age and sex and time trends in prevalence in the model were consistent with study data with the highest simulated prevalences in Kisumu and Ndola, intermediate in Yaoundé and lowest in Cotonou. The sensitivity analysis suggested that the effect of circumcision on the development of the HIV epidemics may have been mediated indirectly by its effect on ulcerative STI.

Conclusions: The contrasting HIV epidemics in east and west Africa could be replicated in our model by assuming that male circumcision reduced susceptibility to HIV, syphilis and chancroid. Varying rates of male circumcision may have played an important role in explaining the strikingly different HIV epidemics observed in different parts of sub-Saharan Africa.
\end{abstract}

$\mathrm{T}$ he HIV epidemic shows considerable heterogeneity within sub-Saharan Africa. The multicentre study of factors determining the different prevalences of HIV in subSaharan Africa (known as the Four Cities Study) was designed to assess whether differences in characteristics of sexual behaviour and/or factors affecting the probability of HIV transmission such as male circumcision or sexually transmitted infections (STIs) could explain the much more severe HIV epidemics observed in east Africa than in west Africa. This cross-sectional, population-based study sampled about 1000 men and 1000 women in each of two cities with relatively low HIV prevalence (Cotonou, Benin, and Yaoundé, Cameroon) and two cities with high HIV prevalence (Kisumu, Kenya, and Ndola, Zambia).

The study found that some biological cofactors for HIV transmission differed between the high and low prevalence cities. In the cities with low HIV prevalence, virtually all the males were circumcised whereas in the cities with high prevalence, the proportion was much lower, 28\% in Kisumu and $10 \%$ in Ndola. $^{2}$ In addition, the prevalence of herpes simplex virus type 2 (HSV-2) was higher among young women and men in the east African cities than in the west African cities. $^{3}$
The study also identified some important differences in reported sexual behaviour between the four populations including younger age at first sexual intercourse and marriage in east Africa than in west Africa and larger age differences between spouses in east Africa. ${ }^{4}$ However, other characteristics of sexual risk behaviour such as reported high partner change rates and having had sex with a sex worker were more prevalent in the cities with low prevalence than in the cities with high prevalence. ${ }^{5}{ }^{6}$ Hence, an important hypothesis raised by the study was that differences in risky sexual behaviour were outweighed by differences in biological cofactors that influence HIV transmission, such as male circumcision and other STIs, especially HSV $-2 .^{4}$

The objective of the present study was to evaluate this hypothesis and determine if the observed differences in risk behaviours, proportions of males circumcised and STI prevalences observed in the four cities could explain the contrasting HIV epidemics. We tested this hypothesis by fitting an individual-based stochastic model to the demographic, behavioural and epidemiological characteristics of the four study

Abbreviations: CSW, commercial sex workers; HSV-2, herpes simplex virus type 2 
populations based on the data from the Four Cities Study as well as other relevant sources. ${ }^{7-17}$ This is the first time a mathematical model portraying the urban populations from all four cities has been presented. In this paper, the results of the simulations and the corresponding model assumptions are presented. Our companion paper in this issue, based on the simulated populations in this paper, explores the changing role of other STIs on HIV transmission over the time course of the epidemics.

\section{METHODS}

To test whether the observed differences in HIV epidemics could be explained by the observed population differences, the transmission model must replicate the demographic, sexual behaviour and epidemiological characteristics of the four urban populations. We first describe the STDSIM model, present a comparison of the empirical data from the Four Cities Study and define a priori plausible ranges for model inputs and outputs. We then describe how the model was fitted to the study data and the sensitivity analysis that was undertaken to evaluate our parameter assumptions.

\section{The STDSIM transmission model}

STDSIM is a flexible individual-level stochastic model that allows simulation of the simultaneous spread of several STIs over time. Individual life histories of people and the sexual interactions between them are simulated. Sexual contacts and relationships form a network through which STIs can be transmitted. The formation and dissolution of partnerships as well as infection transmission are modelled as a sequence of stochastic processes. ${ }^{18}$ Some characteristics of simulated individuals such as sex and date of birth are held constant throughout their life, whereas others such as sexual activity are allowed to vary over time. Characteristics of individuals are then aggregated to give population-level characteristics such as STI prevalence and incidence. ${ }^{18}$
In this study, HIV, chancroid, syphilis, HSV-2, gonorrhoea and chlamydia infection were modelled. The modelled natural history and transmission parameters of these infections were held constant across all four cities and were based on literature reviews and previous STDSIM modelling studies ${ }^{19}$ (table 1). The natural history of each infection was compartmentalised into different stages. Infection transmission was simulated at the level of the individual sex act and interactions between STIs and HIV were modelled using stage-specific cofactor effects which can increase HIV acquisition, infectivity or both. These cofactor effects represent the relative increase in per contact probability of HIV transmission in the presence of other STIs.

For the per contact transmission probabilities for HIV and the other STIs, ranges were defined based on literature reviews. ${ }^{19}$ While modelling the observed differences in sexual behaviour across the sites (see sexual behaviour section below, table 2), the transmission probabilities were fitted within the predetermined ranges such that the model accurately reflected the prevalence of HIV and the other STIs across all four cities. For all modelled STIs, including HIV, the male-to-female transmission probability was set to be two times that of female-to-male.

In the model, HIV was represented by four stages: primary, asymptomatic, symptomatic and AIDS (table 1). The assumed average duration from infection until death from AIDS was 10 years. ${ }^{20}$ The use of four stages for HIV infection allowed us to simulate changes in infectivity over the course of the infection ${ }^{21}$ and changes in effects of HIV on the natural history of HSV-2 that occur only in the later symptomatic and AIDS stages of infection. $^{22} 23$ Infectivity of HIV was simulated as high in the primary stage, lower during the asymptomatic stage and then increasing again during the symptomatic and AIDS stages. ${ }^{24}$ The a priori ranges for HIV transmission probabilities in each stage were based on a recent review of per contact transmission probabilities. $^{25}$

Chancroid was represented as a single infectious stage with an average duration of 11 weeks in males and females and was

\begin{tabular}{|c|c|c|c|c|c|c|c|c|}
\hline \multirow[b]{2}{*}{ Infection and stage } & \multirow[b]{2}{*}{ Duration } & \multicolumn{2}{|c|}{$\begin{array}{l}\text { Transmission } \\
\text { probability per act }\end{array}$} & \multicolumn{2}{|c|}{ Cofactor effects } & \multirow[b]{2}{*}{$\begin{array}{l}\text { Effects of } \\
\text { HIV }\end{array}$} & \multicolumn{2}{|c|}{ Symptomatic (\%)* } \\
\hline & & $M \rightarrow F$ & $\mathbf{F} \rightarrow \mathbf{M}$ & STI on HIV & $\begin{array}{l}\text { Lack of } \\
\text { circumcision on } \\
\text { HIV/STIt }\end{array}$ & & $M$ & $\mathbf{F}$ \\
\hline \multicolumn{9}{|l|}{ HIV } \\
\hline Primary & 10 weeks & 0.028 & 0.014 & & 2 & None & & \\
\hline Asymptomatic & 5 years & 0.002 & 0.001 & & 1 & None & & \\
\hline Symptomatic & 4 years & 0.006 & 0.003 & & 1 & HSV-2 & & \\
\hline AIDS & 40 weeks & 0.014 & 0.007 & & 1 & HSV-2 & & \\
\hline Chancroid & 11 weeks & 0.23 & 0.115 & 25 & 2 & & 90 & 70 \\
\hline Gonorrhoea & $\begin{array}{l}14 \text { weeks } M \text {, } \\
14 \text { weeks } F\end{array}$ & 0.26 & 0.13 & 3 & 1 & & 45 & 14 \\
\hline Chlamydia & $\begin{array}{l}14 \text { weeks } M \text {, } \\
52 \text { weeks } F\end{array}$ & 0.252 & 0.126 & 3 & 1 & & 11 & 6 \\
\hline \multicolumn{9}{|l|}{ Syphilis } \\
\hline Primary & 6 months & 0.175 & 0.088 & 7.5 & 2 & & 50 & 20 \\
\hline Early latent & 1 year & 0.018 & 0.009 & 1 & 1 & & 0 & 0 \\
\hline Latent & 2.5 years & 0 & 0 & 1 & 1 & & 0 & 0 \\
\hline Late latent & 12.5 years & 0 & 0 & 1 & 1 & & 0 & 0 \\
\hline \multicolumn{9}{|l|}{$\mathrm{HSV}-2$} \\
\hline Primary & 3 weeks & 0.3 & 0.15 & 25 & 1 & & & \\
\hline Early latent with recurrent ulcer $\neq$ & 2 years & 0.01 & 0.005 & 1 & 1 & 4 & & \\
\hline Latent with recurrent ulcerł & 10 years & 0.005 & 0.003 & 1 & 1 & 4 & & \\
\hline Late latent & Lifelong & 0 & 0 & 1 & 1 & 4 & & \\
\hline Recurrent ulcer substage & 7 days & 0.2 & 0.1 & 10 & 1 & 4 & NA & \\
\hline \multicolumn{9}{|c|}{ Durations are the same for males and females unless otherwise noted. } \\
\hline \multicolumn{9}{|c|}{ F, female; HSV-2, herpes simplex virus $2 ; M$, male; NA, not applicable. } \\
\hline \multicolumn{9}{|c|}{ *Proportion of symptomatic STls are defined for treatable STls including gonorrhoea, chlamydia, chancroid and syphilis. } \\
\hline \multicolumn{9}{|c|}{ †Pertains to increased acquisition uncircumcised compared with circumcised, males only. } \\
\hline \multicolumn{9}{|c|}{$\begin{array}{l}\text { ‡For HSV-2, recurrent ulcers occur at an average frequency of } 2.5 \text { months for males and three months for females in the early latent stage. For the latent } \\
\text { stage, ulcers recur less frequently, every six months on average for males and every eight months on average for females. }\end{array}$} \\
\hline
\end{tabular}


associated with a high HIV cofactor effect $^{26} 27$ (table 1). Chancroidal ulcers are often described as painful, prompting patients to seek treatment. ${ }^{28}{ }^{29}$ We therefore assumed $50 \%$ of symptomatic males would abstain from sexual activity during chancroid infection. Syphilis was represented by four stages: infectious, early latent, latent and late latent (table 1). Infectious syphilis was simulated to last on average six months and was associated with a high transmission probability and HIV cofactor effect. ${ }^{30}$ The proportion symptomatic was less than for chancroid. ${ }^{31}$ Without treatment, syphilis progresses to noninfectious stages that represent reductions in the titres of rapid plasma reagin over $10-15$ years.

HSV-2 was represented by four stages: primary, early latent, latent and late latent. A primary ulcer was assumed to last an average of three weeks, was highly infectious and was associated with a high HIV cofactor effect. ${ }^{32}{ }^{33}$ After the primary ulcer, ulcers were modelled to recur with decreasing frequency. ${ }^{34}$ Recurrent ulcers were assumed to persist for an average of one week and to be less severe than primary ulcers with lower infectivity and HIV cofactor effects. ${ }^{32}$ Primary ulcers were also assumed to be more often recognised than recurrent ulcers. ${ }^{35}$ In between recurrences, a low continuous level of infectivity was assumed, representing subclinical shedding in those infected with HSV-2, ${ }^{36}{ }^{37}$ but no cofactor effect on HIV was assumed. In the final modelled stage, individuals did not have ulcers but remained seropositive for life. Study results suggest that the frequency and duration of ulcerative recurrences increase during the symptomatic and AIDS stages of HIV infection. ${ }^{22}{ }^{23}$ The magnitude of this effect is not known precisely and we assumed that frequency and duration were each qudrupled during these stages.

Both chlamydia and gonorrhoea were represented by one infectious stage with a low HIV cofactor effect. The average duration of infection was 14 weeks for gonorrhoea and chlamydia in males. Chlamydia in females lasted a year. ${ }^{38} 39$ To achieve an adequate model fit of the observed rapid decline in chlamydia prevalence with age, each episode of chlamydia infection was assumed to induce a $20 \%$ reduction in susceptibility to reinfection, in line with observations on acquired immunity to ocular Chlamydia. ${ }^{40}$ The proportion symptomatic was assumed to be less than for syphilis and chancroid (table 1).

STI cofactor effects on HIV acquisition and transmission per sexual contact are not known precisely. ${ }^{41}{ }^{42}$ Our assumed values were based on previous STDSIM studies ${ }^{19}$ and are in line with the relative clinical severity of the various STIs (table 1). Chancroid and primary HSV-2 infection were assumed to have the highest per contact cofactor effects for HIV transmission (increasing the transmission probability per contact by a factor of 25) and gonorrhoea and chlamydia infection the lowest (increasing by a factor of 3). The effects of male circumcision were modelled by assuming the probabilities of HIV, syphilis and chancroid acquisition were doubled in uncircumcised males in unprotected contacts with infected partners. ${ }^{43-45}$ Similar to rates measured in the Four Cities Study, the proportion of males circumcised was taken as $100 \%$ in Cotonou and Yaoundé, 25\% in Kisumu and $10 \%$ in Ndola. ${ }^{2}$ For the STIs, the cofactor effects for HIV acquisition and transmission were assumed to be equal. If more than one cofactor (including for STIs and lack of circumcision) was present during a simulated sexual contact, only the highest cofactor effect was applied.

Three different types of sexual relationship are modelled including steady (marriages), short term and one-off contacts with commercial sex workers (CSWs). The rate of sex partner change in the model is determined by a supply and demand mechanism in which individuals search for an available sex partner. ${ }^{18}$ Demand and availability of partners depends on age, sex and marital status. These parameters result in model outputs that can be compared with study data on the proportions married, the distribution of reported number of non-marital sex partners in the past year and the number of lifetime partners.

\section{Data comparison and plausible ranges for model inputs and outputs}

The initial step in fitting the model to the study data was to define a priori plausible ranges for certain model inputs and outputs based on the study data and other relevant data sources. We determined which demographic and sexual behaviour characteristics were allowed to vary across the sites by comparing relevant data from the original study and other data sources including Demographic and Health Surveys and antenatal surveillance data.

We compared several demographic characteristics including the fertility rate, population composition by age and sex, population growth rates and sex ratios. The most critical demographic characteristic of the population to be fitted was the population composition at the time of the study in 1997 as

Table 2 Sexual behaviour characteristics for the four cities

\begin{tabular}{|c|c|c|c|c|c|c|c|c|}
\hline & \multicolumn{2}{|c|}{ Cotonou } & \multicolumn{2}{|c|}{ Yaoundé } & \multicolumn{2}{|c|}{ Kisumu } & \multicolumn{2}{|c|}{ Ndola } \\
\hline & $\bar{M}$ & $F$ & $M$ & $\mathbf{F}$ & $M$ & $F$ & $M$ & $\mathbf{F}$ \\
\hline Debut age (median, years) & 18.2 & 18.3 & 17.1 & 17 & 16.1 & 15.8 & 17.4 & 16.7 \\
\hline Married (\%) & 40.9 & 55.0 & 34.5 & 44.0 & 53.2 & 62.8 & 51.1 & 57.4 \\
\hline \multicolumn{9}{|l|}{$\begin{array}{l}\text { Distribution of non-marital } \\
\text { partners in past year (\%) }\end{array}$} \\
\hline $0-1$ & 83.5 & 97.8 & 55.2 & 86.2 & 81.9 & 96.3 & 85.3 & 98.8 \\
\hline $2-4$ & 15.5 & 2.2 & 38.6 & 12.9 & 17.1 & 3.7 & 12.4 & 1.0 \\
\hline $5+$ & 1.0 & 0 & 6.3 & 0.9 & 1.0 & 0 & 2.4 & 0.2 \\
\hline \multicolumn{9}{|l|}{$\begin{array}{l}\text { Distribution of partners in } \\
\text { lifetime (\%) }\end{array}$} \\
\hline $0-1$ & 22.4 & 40.6 & 13.7 & 26.2 & 17.3 & 27.5 & 20.1 & 49.1 \\
\hline $2-9$ & 57.2 & 58.8 & 33.4 & 61.7 & 56.4 & 71.8 & 58.1 & 49.5 \\
\hline $10+$ & 20.4 & 0.5 & 53.0 & 12.1 & 25.8 & 0.7 & 21.8 & 1.4 \\
\hline $\begin{array}{l}\text { Condom use in last casual } \\
\text { contact }(\%)\end{array}$ & 26.0 & 15.1 & 25.9 & 18.1 & 28.5 & 25.6 & 29.7 & 28.7 \\
\hline \multicolumn{9}{|l|}{ CSW characteristics } \\
\hline Ratio of CSW/100 men & & 1.0 & & 1.5 & & 2.0 & & 1.9 \\
\hline No. of clients in past week & & 7 & & 2 & & 1 & & 3 \\
\hline Condom use in last contact $1 \%$ & & 69 & & 28 & & 50 & & 28 \\
\hline
\end{tabular}


this determines the number of available sex partners by age and sex. The demographic fit to the data was deemed acceptable if the simulated population composition was within $10 \%$ of the data for each age and sex group from recent censuses and analyses of demographic data ${ }^{17}{ }^{46}$ ( $S$ Kinyanjui, personal communication, 2004) and the population growth rates reflected similar patterns to those measured in recent censuses. The growth rate was highest in Yaoundé $(6.8 \%)$, lowest in Kisumu (2.3\%) and intermediate in Cotonou and Ndola (4\%).

For sexual behaviour, the age of sexual debut, age patterns in marriage, partner change rates, changes in sexual behaviour over time, condom use and characteristics of commercial sex were compared across the four cities (table 2). The differences in behaviour between the sites include younger ages of sexual debut in the east African sites; higher proportions married in Kisumu and Ndola, lower rates in Cotonou and the lowest in Yaoundé; and highest partner change rates in Yaoundé, similar rates in Kisumu and Ndola and lowest rates in Cotonou. ${ }^{5}$ The proportion reporting condom use in their last casual contact was slightly higher in the east African than in the west African sites $^{47}$ ( table 2) so our a priori assumption was that condom use should be slightly higher in east Africa compared with west Africa (table 3). Study data and other sources indicated characteristics of commercial sex also varied across the cities. In Cotonou, there was a relatively low number of sex workers with clients who visit them often compared to Yaoundé and the east African sites ${ }^{68-50}$ (table 2).

\section{Sensitivity analysis}

Based on the study data, and after considering reporting and selection biases, plausible ranges for model outputs were defined for proportions married, distributions of numbers of non-marital sex partners in the past year, and the size and characteristics of the core group-that is, commercial sex workers (CSW) and their clients (table 3). In all sites, the number of reported non-marital sex partners in the past year was higher for males than for females. The reporting of sexual behaviour probably reflects biases due to sample selection (under inclusion of high-risk individuals) and social desirability (leading to under-reporting of high-risk behaviour among women). ${ }^{51}$ Due to these biases we attempted to fit reported male behaviours as reporting bias was assumed to be less for males than females. To account for the possible underrepresentation of high-risk individuals in the study sample, our a priori ranges for model outputs reflect higher than observed numbers of non-marital sex partners in the past year rather than lower than observed (table 3 ).

To assess whether a reduction in risky sexual behaviour had occurred prior to 1997 in the east African sites, we compared the reported numbers of recent and lifetime sex partners between sites. If behaviour change had taken place in Kisumu and Ndola, we would have expected to see higher numbers of lifetime partners but lower numbers of recent partners in these sites than in Cotonou and Yaoundé. In Yaoundé, about $50 \%$ of males reported two or more non-marital sex partners in the past year while similar numbers were reported for males in Cotonou (18\%), Kisumu (18\%) and Ndola (16\%). Comparing lifetime numbers of partners, the most partners were again reported in Yaoundé and similar numbers were reported for the other three sites (table 2). These findings do not point to a significant shift towards safer sexual behaviour in Kisumu and Ndola. Hence, our a priori assumption is that the partner change rate has not varied over the time course of the epidemic in Kisumu and Ndola (table 3).

Table 3 A priori plausible bounds for sexual behaviour and sexually transmitted infection (STI) treatment characteristics of simulated populations and plausible ranges for model outputs

\begin{tabular}{|c|c|c|c|c|}
\hline Parameter & Cotonou & Yaoundé & Kisumu & Ndola \\
\hline \multicolumn{5}{|l|}{ Characteristics } \\
\hline \multicolumn{5}{|l|}{ Sexual debut } \\
\hline Age (years) & $18 \mathrm{M}, 18 \mathrm{~F}$ & $17 \mathrm{M}, 17 \mathrm{~F}$ & $17 \mathrm{M}, 15 \mathrm{~F}$ & $17 \mathrm{M}, 15 \mathrm{~F}$ \\
\hline \multirow[t]{2}{*}{ Range } & \pm 3 years $M$ & \pm 3 years $M$ & \pm 3 years $M$ & \pm 3 years $M$ \\
\hline & \pm 4 years $F$ & \pm 4 years $F$ & \pm 4 years $F$ & \pm 4 years $F$ \\
\hline$V$ other sites & $>$ all & $<$ Cot, $>$ Kis, Nd & $<$ Cot, $\mathrm{Ya}_{1}=\mathrm{Nd}$ & $<$ Cot, $\mathrm{Ya},=\mathrm{Nd}$ \\
\hline \multicolumn{5}{|l|}{ Partner change rate } \\
\hline Factor $^{*}$ & 1 & $>>1$ & $\geqslant 1$ & $\geqslant 1$ \\
\hline \multicolumn{5}{|l|}{ Change in sexual behaviour } \\
\hline over time & No & No & No & No \\
\hline Condom use in non-marital & $10-20 \%$ in early & $10-20 \%$ in early & $10-30 \%$ in early & $10-30 \%$ in early \\
\hline partnerships & 1990 s & $1990 \mathrm{~s}$ & $1990 \mathrm{~s}$ & $1990 \mathrm{~s}$ \\
\hline \multicolumn{5}{|l|}{ CSW characteristics } \\
\hline Start age minimum (years) & 17 & 17 & 17 & 17 \\
\hline Start age maximum (years) & 30 & 30 & 30 & 30 \\
\hline Minimum duration career (years) & 1 & 1 & 1 & 1 \\
\hline Clients/week & Highest & $<$ Cotonou & Lowest & $<$ Cotonou \\
\hline No. of CSW visited/client & Highest & $\leqslant$ Cotonou & $<$ Cotonou & $<$ Cotonou \\
\hline Condom use & $\geqslant 50 \% 1997$ & $<$ Cotonou & $\leqslant$ Cotonou & $=$ Yaoundé \\
\hline STI treatment & Highest & $<<$ Cotonou & $<$ Cotonou & $<<$ Cotonou \\
\hline \multicolumn{5}{|l|}{ Plausible ranges for model outputs } \\
\hline Marriage (\%) & $41 \mathrm{M}, 55 \mathrm{~F}$ & $35 \mathrm{M}, 44 \mathrm{~F}$ & $53 \mathrm{M}, 63 \mathrm{~F}$ & $51 \mathrm{M}, 57 \mathrm{~F}$ \\
\hline Range & $\begin{array}{l}37-45 M \\
49-61 \mathrm{~F}\end{array}$ & $\begin{array}{l}32-40 \mathrm{M} \\
40-48 \mathrm{~F}\end{array}$ & $\begin{array}{l}48-58 \mathrm{M} \\
58-69 \mathrm{~F}\end{array}$ & $\begin{array}{l}46-56 M \\
51-63 F\end{array}$ \\
\hline \multicolumn{5}{|l|}{$\begin{array}{l}\text { Distribution of non-marital partners } \\
\text { in past year for males (\%) }\end{array}$} \\
\hline $0-1$ & $65-75$ & $45-55$ & $65-75$ & $65-75$ \\
\hline $2-4$ & $20-30$ & $40-50$ & $20-30$ & $20-30$ \\
\hline $5+$ & $5-7$ & $7-12$ & $5-7$ & $5-7$ \\
\hline \multicolumn{5}{|l|}{ CSW } \\
\hline$\% M$ that visit CSW & $12-30 \%$ & $\geqslant$ Cotonou & $<$ Cotonou & $\geqslant$ Cotonou \\
\hline$\%$ CSW & $\sim 1 \%$ & $>$ Cotonou & $>>$ Cotonou & $>>$ Cotonou \\
\hline HIV \%+ among CSW & $40-60 \%$ & $34-50 \%$ & $70-80 \%$ & $70-80 \%$ \\
\hline
\end{tabular}

Cot, Cotonou; CSW, commercial sex worker; F, female; Kis, Kisumu; M, male; Nd, Ndola; Ya, Yaoundé.

*The partner change rate factor denotes how much higher or lower the partner change rate should be for each site compared with Cotonou. 
Table 4 Input parameters and fitted values for sexual behaviour, treatment of sexually transmitted infections (STIs) and commercial sex in the Four Cities Study

\begin{tabular}{|c|c|c|c|c|c|c|c|c|}
\hline & \multicolumn{2}{|c|}{ Cotonou } & \multicolumn{2}{|c|}{ Yaoundé } & \multicolumn{2}{|l|}{ Kisumu } & \multicolumn{2}{|c|}{ Ndola } \\
\hline \multicolumn{9}{|l|}{ Model inputs } \\
\hline \multicolumn{9}{|l|}{ General population } \\
\hline Partner change & \multicolumn{2}{|l|}{ Lowest } & \multicolumn{2}{|c|}{ Highest } & \multicolumn{2}{|c|}{$>$ Cot, $<\mathrm{Nd}$} & \multicolumn{2}{|c|}{$<\mathrm{Ya}_{\text {, }}>$ Kis } \\
\hline Change in partner change rate over time & \multicolumn{2}{|l|}{ No } & \multicolumn{2}{|c|}{ Increase in 1993} & \multicolumn{2}{|c|}{ No } & \multicolumn{2}{|c|}{ No } \\
\hline Age of debut (years) & \multicolumn{2}{|c|}{ M: 18, F: 18} & \multicolumn{2}{|c|}{$M: 17, F: 17$} & \multicolumn{2}{|c|}{$M: 17, F: 15$} & \multicolumn{2}{|c|}{$M: 17, F: 15$} \\
\hline \multirow[t]{2}{*}{ Condom use in non-marital partnerships } & \multirow{2}{*}{\multicolumn{2}{|c|}{$\begin{array}{l}10 \% \text { in } 1990 \\
20 \% \text { in } 1995\end{array}$}} & \multirow{2}{*}{\multicolumn{2}{|c|}{$\begin{array}{l}10 \% \text { in } 1990 \\
20 \% \text { in } 1995\end{array}$}} & \multirow{2}{*}{\multicolumn{2}{|c|}{$\begin{array}{l}10 \% \text { in } 1990 \\
25 \% \text { in } 1995\end{array}$}} & $10 \%$ ir & \\
\hline & & & & & & & $25 \%$ ir & \\
\hline Default ST (cured (\%)|* & M & $\mathrm{F}$ & M & $\mathrm{F}$ & M & $\mathrm{F}$ & M & $\mathrm{F}$ \\
\hline NG & 2.7 & 0.6 & 2.7 & 0.6 & 2.7 & 0.6 & 2.7 & 0.6 \\
\hline CT & 0.7 & 0.3 & 0.7 & 0.3 & 0.7 & 0.3 & 0.7 & 0.3 \\
\hline Syphilis & 5 & 1.5 & 5 & 1.5 & 5 & 1.5 & 5 & 1.5 \\
\hline$H D$ & 0 & 0 & 0 & 0 & 0 & 0 & 0 & 0 \\
\hline Improved ST (year) & 1995 & & 1992 & & 1992 & & 1992 & \\
\hline (cured $(\%))^{*}$ & M & $\mathrm{F}$ & M & $\mathrm{F}$ & M & $\mathrm{F}$ & M & $\mathrm{F}$ \\
\hline NG & 8.1 & 1.7 & 13.5 & 3.4 & 13.5 & 3.4 & 8.1 & 1.7 \\
\hline CT & 2.0 & 0.7 & 3.3 & 1.4 & 3.3 & 1.4 & 2.0 & 0.7 \\
\hline Syphilis & 12.0 & 3.6 & 18 & 6 & 18 & 6 & 12.0 & 3.6 \\
\hline $\mathrm{HD}$ & 21.6 & 12.6 & 32.4 & 21 & 32.4 & 21 & 21.6 & 12.6 \\
\hline Commercial sex & & & & & & & & \\
\hline Clients/week & 4 & & 2 & & 1 & & 2 & \\
\hline Client visiting frequency (visits/year) $†$ & 0,2 , & & 0,1, & & $0,1,1$ & & 0,1 , & \\
\hline \% Clients/class $\ddagger$ & & & & & & & & \\
\hline Single & 0.51 & $40,0.09$ & 0.29 , & $.59,0.12$ & 0.27, & $.61,0.12$ & 0.15 & $65,0.20$ \\
\hline Married & 0.79 & $21,0.004$ & 0.65 , & $29,0.06$ & 0.64 & $30,0.06$ & 0.6 & $5,0.05$ \\
\hline Change in CSW parameters over time & No & & Increas & in 1993 & No & & No & \\
\hline Condom use & $10 \%$ in & & $10 \%$ in & 990 & $10 \%$ in & 990 & $10 \%$ ir & \\
\hline & $25 \%$ ir & & $20 \%$ in & 993 & $20 \%$ in & 993 & $20 \%$ ir & 993 \\
\hline & $50 \%$ in & & $30 \%$ in & 995 & $30 \%$ in & 995 & $30 \%$ ir & 995 \\
\hline STI screening & & & & & & & & \\
\hline Frequency & Month & & $3 \mathrm{mont}$ & & $3 \mathrm{mont}$ & & $1 \mathrm{mon}$ & \\
\hline Coverage (\%) & $10 \%$ ir & & $10 \%$ in & 993 & $10 \%$ in & 993 & $10 \%$ ir & \\
\hline & $40 \%$ ir & & $25 \%$ in & 995 & $25 \%$ in & 995 & $25 \%$ in & 995 \\
\hline Model outputs & & & & & & & & \\
\hline Numbers of non-marital partners in past yec & or males & & & & & & & \\
\hline 1 & 76.5 & & 57.3 & & 64.5 & & 60 & \\
\hline $2-4$ & 22.2 & & 34.7 & & 30.7 & & 33.9 & \\
\hline $5+$ & 1.3 & & 8.0 & & 4.8 & & 6.1 & \\
\hline$\%$ CSWs & 0.7 & & 1.8 & & 2.3 & & 1.3 & \\
\hline$\%$ Clients by no. of visits & & & & & & & & \\
\hline 1 & 7.4 & & 19.8 & & 12.9 & & 14.6 & \\
\hline $2-4$ & 13.7 & & 13.6 & & 9.1 & & 10.3 & \\
\hline $5+$ & 5.4 & & 11.3 & & 6.2 & & 8.2 & \\
\hline HIV prevalence among CSWs & 50.3 & & 34.8 & & 70.7 & & 65.4 & \\
\hline $\begin{array}{l}\text { Cot, Cotonou; } \mathrm{F} \text {, female; } \mathrm{M} \text {, male; Kis, Kisu } \\
* \% \text { cured }=\% \text { symptomatic } \times \% \text { seeking tre } \\
\dagger \text { The frequency at which males visit CSWs } \\
\text { †The proportion of clients in each visiting cl }\end{array}$ & $\begin{array}{l}; \mathrm{Nd}, \mathrm{N} \\
\text { ent } \times \text { tr } \\
\text { vided in } \\
\text { for mar }\end{array}$ & $\begin{array}{l}\text { a; ST, synd } \\
\text { ment efficac } \\
\text { three classe } \\
\text { and single }\end{array}$ & $\begin{array}{l}\text { Iromic t } \\
\text { cy. } \\
\text { s. }\end{array}$ & nent; $Y_{0}$ & uoundé. & & & \\
\hline
\end{tabular}

The level and timing of effective STI treatment based on available information from the four sites at the time of the study indicated treatment was slightly better in Yaoundé and Kisumu compared with the other cities. ${ }^{52}$ The $95 \%$ confidence intervals for the age- and sex-specific HIV prevalences and STI prevalences as measured during the study ${ }^{1}$ provided the plausible ranges for the fit of the model to the epidemiological data. The time trend in HIV prevalence was based on available data from antenatal clinic attenders. ${ }^{53}{ }^{54}$ The initial spread of HIV in a population depends on the sexual behaviour of a few individuals a long time ago and is likely to have a large stochastic element. The date of HIV introduction was therefore allowed to vary slightly across the sites to better fit the time trend in HIV prevalence.

\section{Fitting the STDSIM model to study data and model assumptions}

Fitting the model representations to the data from the Four Cities Study was an iterative process taking into account those model parameters that were allowed to vary across sites (fertility rates, mortality, age of sexual debut, probabilities of entering steady or short relationships by age, changes in rates of formation of relationships over time, use of condoms, aspects of commercial sex and treatment of STI) and those that were restricted to be held constant (natural history, transmission probabilities and interactions of all the infections).

Demographic outputs including the age and sex population composition and growth rates were fitted first, then behavioural outputs including the proportions married, distribution of numbers of non-marital partners in the past year and the characteristics of commercial sex. Once the model representations reflected the sexual behaviour characteristics of the four populations, epidemiological model outcomes including HIV and STI prevalences by age and sex and time trends in HIV prevalence were compared with the available data. If the fit did not reflect the correct epidemiological patterns as observed across the sites, the inputs were varied within the a priori ranges and sometimes outside these ranges if a good fit could not be found. The simulation period was 1910-2000 and the results are based on the average of 200 simulations. Model 

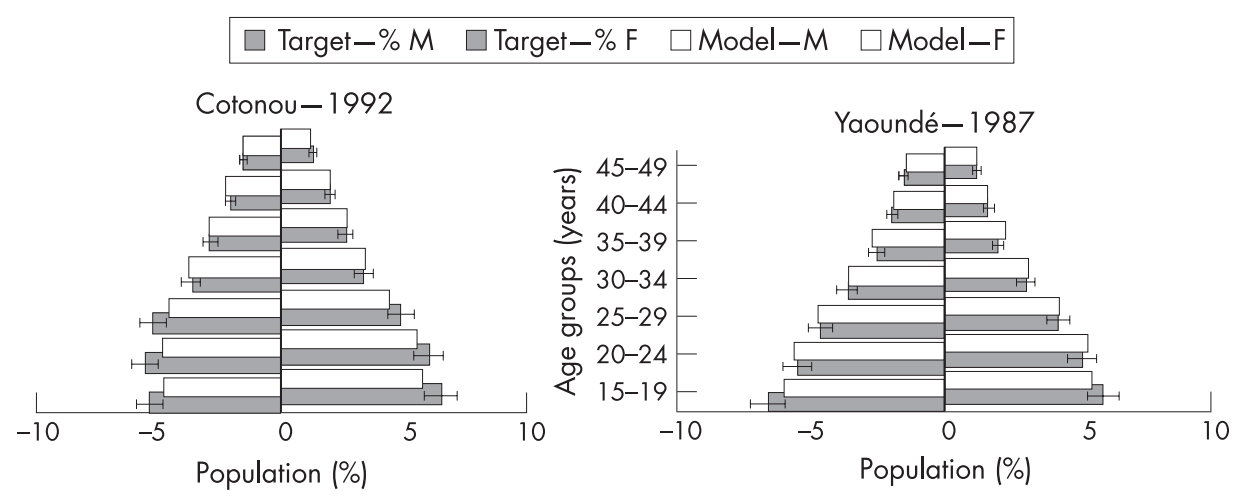

Figure 1 Observed and simulated population structure by age and sex for the four cities. Grey bars represent data, white bars are the model projections. Data for males on left, females on right. Error bars reflect $\pm 10 \%$ for each age and sex group and acceptable range for model fit.

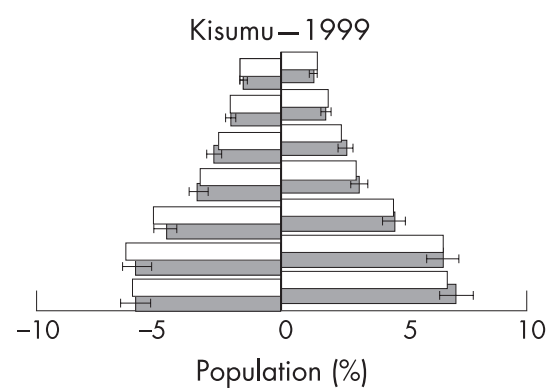

Population (\%)

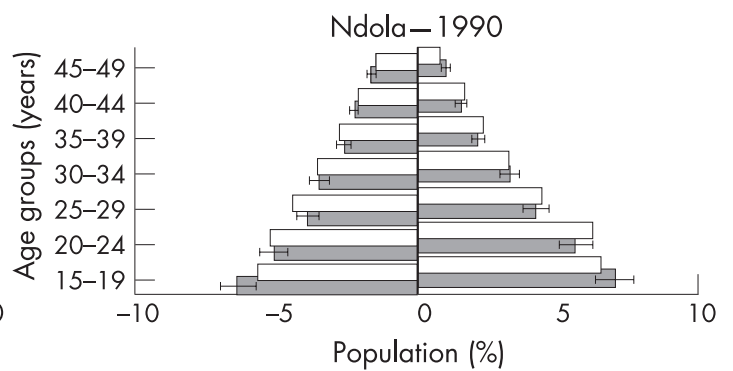

outputs from the year 1997 were compared with the study data. The modelled differences in behaviour between the sites include younger ages of sexual debut in the east African sites; higher proportions married in Kisumu and Ndola, lower rates in Cotonou and the lowest in Yaoundé; highest partner change rates in Yaoundé, similar rates in Kisumu and Ndola and lowest rates in Cotonou 5 ; and higher number of CSW clients per week in Cotonou than in the other three $\operatorname{sites}^{6}$ (table 4 ). Low rates of condom use were simulated for the general population in all four sites starting in 1990 and increased in 1995 such that condom use was slightly higher in east Africa than in west Africa at the time of the study (table 4).

The modelled proportion cured for each STI is a product of the proportion symptomatic, the proportion seeking treatment and treatment efficacy. Before the early 1990s a low level of syndromic treatment was assumed $(0-5 \%$ of gonorrhoea, chlamydia infection, syphilis and chancroid were cured). The effectiveness of STI treatment was increased slightly in the early 1990s to reflect recent improvements in these urban centres. The modelled proportion of symptomatic STI episodes cured increased to 30\% in Yaoundé and Kisumu in 1992, to $18 \%$ in Ndola in 1992 and to $18 \%$ in Cotonou in 1995 (table 4).

Simulated STI screening and treatment among CSWs was most effective in Cotonou where it was assumed to be frequent (monthly) and with increasing coverage up to $40 \%$ in $1995 .{ }^{55}$ Screening was assumed to be less frequent (every three months) and at lower coverage (25\% in 1995) for CSWs in Yaoundé and Kisumu. In Ndola, screening was assumed to take place monthly at low coverage (table 3 ). These assumptions were made to help fit the differentials in curable STI prevalences between females in the general population and CSWs. In Yaoundé, we modelled an increase in rates of partner change and male visiting of sex workers starting in 1993. This increase in risky sexual behaviour was simulated to help fit the increasing trend in HIV prevalence over time observed for Yaoundé. ${ }^{56}$ Condom use among sex workers was simulated to be highest in Cotonou and lower in the other three sites (table 4).

We undertook a sensitivity analysis to assess the influence of selected parameters such as STI and lack-of-circumcision cofactor effects, specific behavioural characteristics (eg, condom use, STI screening among sex workers) and chancroid epidemiology on the prevalence of HIV, gonorrhoea and chancroid among women in the general population and among sex workers in 1997. The default scenarios for Cotonou and Ndola were used as examples in the sensitivity analysis because these two quantifications represented extremes in sexual behaviour profiles and the proportion of males circumcised.

\section{RESULTS}

\section{Model fit to data}

The model adequately replicates the age and sex composition of the four cities as measured by recent censuses (fig l) as well as the sex ratios for the sexually active age groups (not shown). Figure 2 shows the fit for proportions married by age and sex. Males and females in east Africa marry at younger ages than those in west Africa and the model fit accurately reflects this pattern. Simulated age differences between steady partners were slightly lower in Cotonou (five years) compared with the other sites (about six years), consistent with the study data. Also, reported polygamy was highest in Cotonou and Kisumu. In the model, polygamy is higher in Ndola (7\% model, $3 \%$ data) than Cotonou ( $3 \%$ model, $6.5 \%$ data) to fit the higher proportions married in Ndola compared with Cotonou. The model did not provide a good fit to the prevalence of polygamy in the four sites, but this was not a major concern because this magnitude of difference in polygamy between the sites will not substantially affect epidemiological outcomes.

As reflected in the data, the highest partner change rate was simulated for Yaoundé (proportion of men with five or more non-marital partners in the past year, data $=6.3 \%$, model $=8.0 \%$ ), then Ndola (data $=2.4 \%$, model $=6.1 \%$ ) and the lowest rates are for Kisumu (data $=1 \%$, model $=4.7 \%$ ) and Cotonou ( data $=1 \%$, model $=1.3 \%$ ). The simulated partner change rate for Cotonou was lower than our a priori range to fit the low HSV-2 prevalence observed in Cotonou. The proportion of females who are sex workers was simulated to be lowest in Cotonou (table 4), as observed. The simulated proportion of males who visit sex workers often is higher in Yaoundé (11.3\%) 


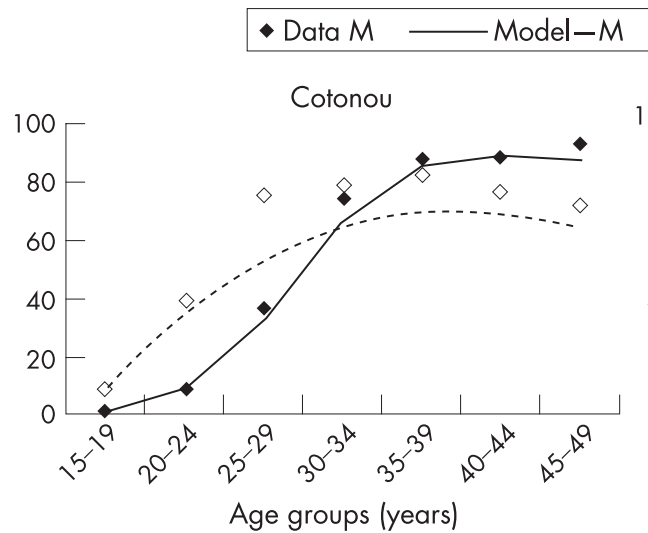

\section{$\diamond$ Data F - - - - Model-F}
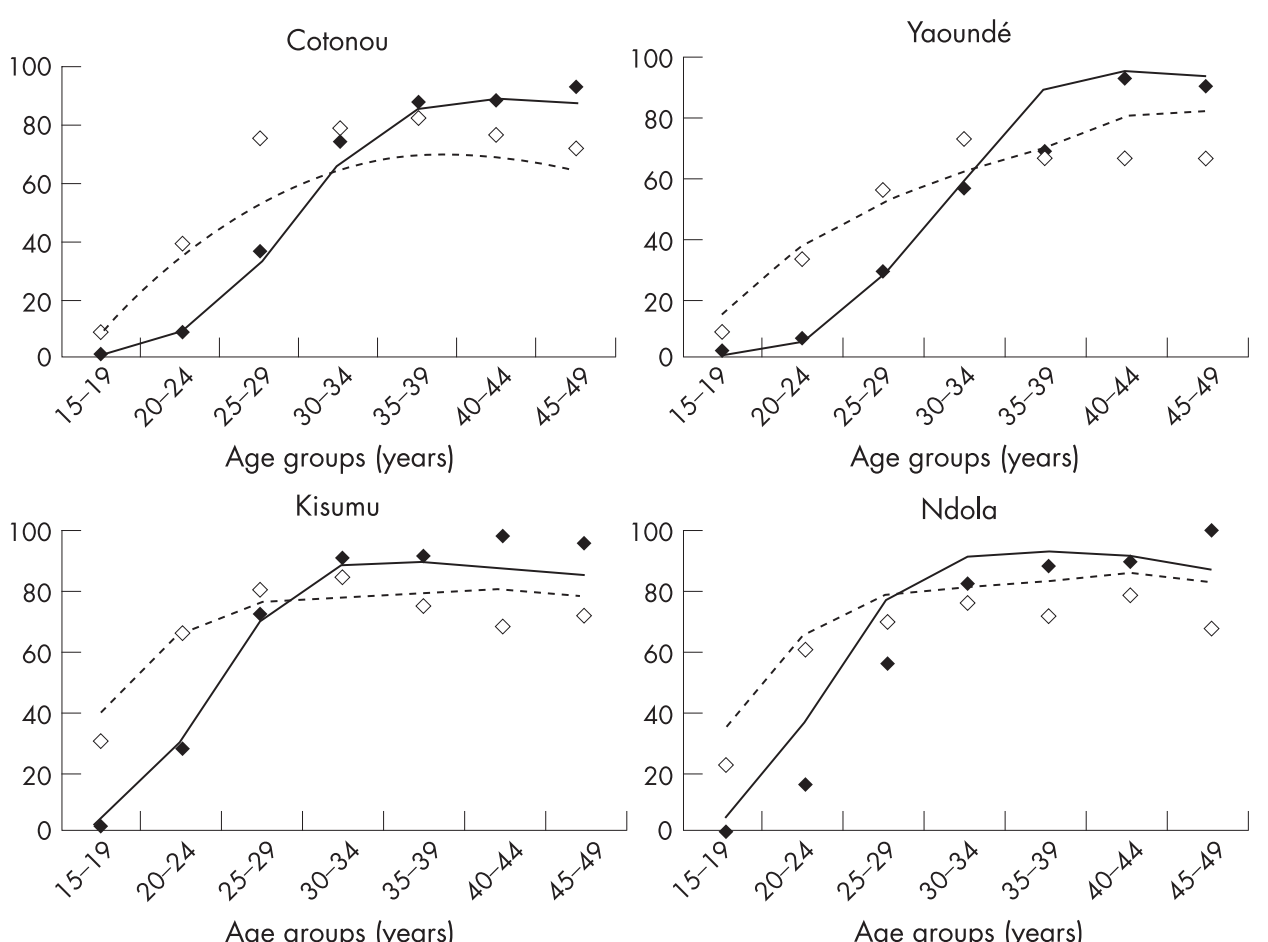

Age groups (years)
Figure 2 Simulated and actual proportions married by age and sex for the Four Cities Study in 1997. Points reflect data, lines reflect model fit in 1997. and Ndola (8.2\%) than in Cotonou (5.4\%) and Kisumu (6.2\%), consistent with our a priori ranges (tables 3 and 4).

The model provided a reasonable fit to the age and sex patterns in HIV prevalence in all sites (fig 3). The model replicated the observed patterns, including the much higher HIV prevalence among young females compared with young males. In Cotonou, HIV prevalence was very similar among males and females, as observed. For Yaoundé, the peak age in prevalence was slightly younger in females than males as observed in the data but prevalence among young males was slightly overestimated. For Kisumu and Ndola the patterns in prevalence were similar to that for Yaoundé with peak prevalence in females slightly younger than in males.

As a further assessment of the fit, simulated STI prevalences among all females were compared with those for CSWs (fig 4). This contrast provides insight into how well the simulated sexual behaviour reflects the situation in the sites at the time of the study. The fit for Cotonou is good as the contrast in prevalences of short and long duration STI among females and CSWs is reflected by the model. In Yaoundé, the fit is also acceptable but the prevalence of ulcers (the sum of the point prevalence for those with primary syphilis, chancroid and the ulcerative stages of HSV-2) among CSWs was lower in the data than in the model and the prevalence of gonorrhoea was overestimated among the CSWs.

In east Africa, the fit is reasonable (fig 4). In Kisumu, the simulated prevalence of ulcers was higher among CSWs than in the data. The prevalence of syphilis was overestimated slightly in the model. In Ndola, the contrasts for females and the sex workers were consistent with the data except that the prevalence of syphilis among CSWs was underestimated in the model. The prevalence among sex workers was extremely high $(42 \%)$ in the study and it would be difficult to fit this without making some specific assumptions regarding the dynamics of syphilis in Ndola (eg, that syphilis was epidemic and not endemic at the time of the study). Figure 5 shows available data on time trends in HIV prevalence among antenatal clinic attendees and the simulated prevalence over time from the model. In general, we would expect the simulated prevalences to be higher than those among ANC attendees because the latter have been shown to underestimate HIV prevalence among the general population. ${ }^{57}$ The model fits the observed trends across the four cities reasonably well. To accurately reflect the trend we introduced HIV earlier in Kisumu (1980) than in the other sites (1984).

\section{Sensitivity analysis}

The sensitivity analysis illustrates which factors may be important for the development of the HIV epidemics over time in these cities. It shows that in both the Cotonou and Ndola scenarios the magnitude of the STI cofactor effects have a large impact on the development of the HIV epidemics (table 5). In Cotonou, however, non-ulcerative STIs were more important for HIV spread whereas in Ndola ulcerative STIs seem to have been the main determinant. This can be deduced by comparing HIV prevalence in the test scenarios where all cofactors were varied with that for the scenario when only the ulcerative cofactors were varied. This is primarily due to the marked difference in the contribution of chancroid to the spread of HIV in the first 15 years of the epidemics in Ndola and Cotonou; see figure $2 \mathrm{~B}$ in our companion paper in this issue. ${ }^{58}$

The sensitivity analysis suggests the direct protective effect of circumcision on HIV acquisition in males may not have had much impact on the development of the HIV epidemics in the four cities. If the lack-of-circumcision cofactor effect on HIV was doubled from 2 to 4 (in a scenario in which $10 \%$ of males were circumcised), the simulated prevalence of HIV among women in the Ndola scenario in 1997 increased from $29.7 \%$ to $31.5 \%$. However, when the lack-of-circumcision cofactor effects for HIV, chancroid and syphilis were all increased there was a much larger impact on the subsequent development of the HIV epidemic, so that the HIV prevalence in 1997 increased from $29.7 \%$ to $41 \%$ and chancroid prevalence increased from $0.1 \%$ to $0.8 \%$. This occurred because in our simulations circumcision 
- Data M - Model-M
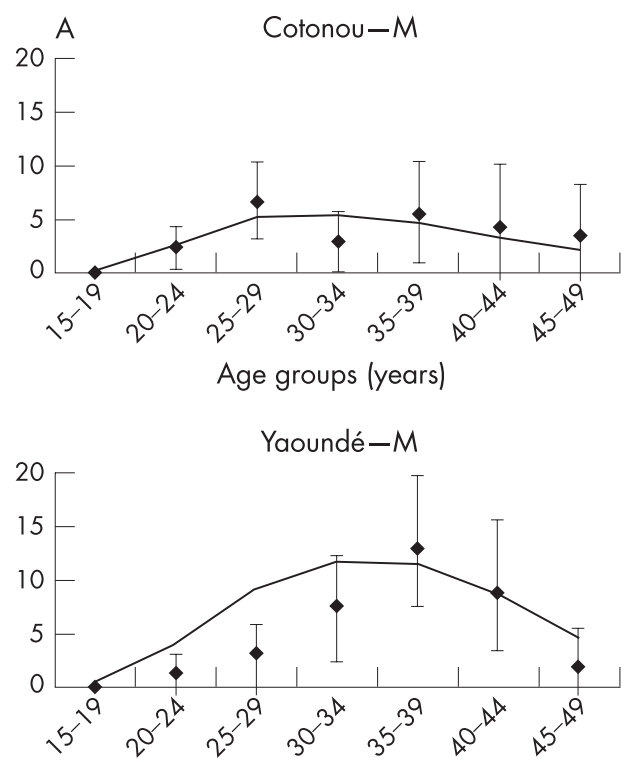

Age groups (years)
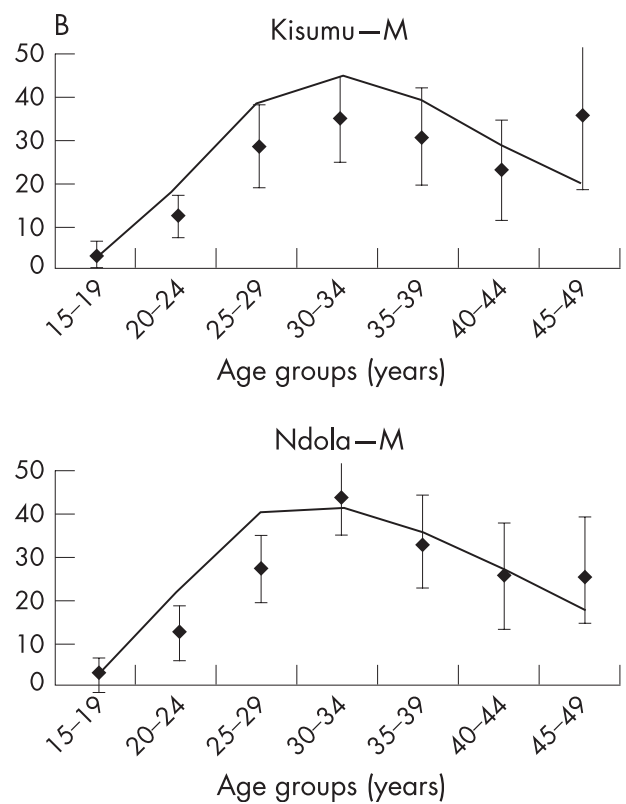

Figure 3 Observed (mean, 95\% Cl) and simulated HIV prevalence by age and sex for the Four Cities Study in 1997. Males on left, females on right. Note differing y axis scales. (A) West Africa. (B) East Africa. affects the prevalence of chancroid, which in turn has been shown to be a strong determinant of the rapid spread of HIV in early epidemics. ${ }^{59}$ If simulated chancroid prevalence among females in 1997 is increased in the Ndola scenario from $0.1 \%$ to $2 \%$ (by increasing the chancroid transmission probability), HIV prevalence increases from $29.7 \%$ to $57.6 \%$ (table 5 ). Hence, our simulations suggest that most of the protective effect of circumcision on HIV transmission during the growth phase of the epidemics may have occurred indirectly through its effect on chancroid prevalence.

The use of condoms had a large impact on the prevalence of short-duration STIs as expected. Decreasing the screening frequency of CSWs in Cotonou improved the fit for shortduration STIs in the general population but greatly increased gonorrhoea prevalence among CSWs. Similarly, in Ndola, increasing treatment coverage of CSWs improved the fit for gonorrhoea in the general population but worsened it for CSWs.
The probability that males will abstain from sex during chancroid infection also had a large impact on the results. The default scenario assumed $50 \%$ of males abstain during infection. If we assumed no change in coital frequency during chancroid infection, both chancroid and HIV prevalence increased significantly (table 5).

\section{DISCUSSION}

The objective of this study was to determine if we could replicate the striking variations in the HIV epidemics as observed in Cotonou, Yaoundé, Kisumu and Ndola by simulating the observed patterns in demography, sexual behaviour, STI and circumcision from the Four Cities Study. By comparing the available data from the study and defining reasonable fit criteria we were able to fit the STDSIM model to the contrasting HIV epidemics in east and west Africa. Our model fit assumed the patterns of sexual behaviour were as observed during the 


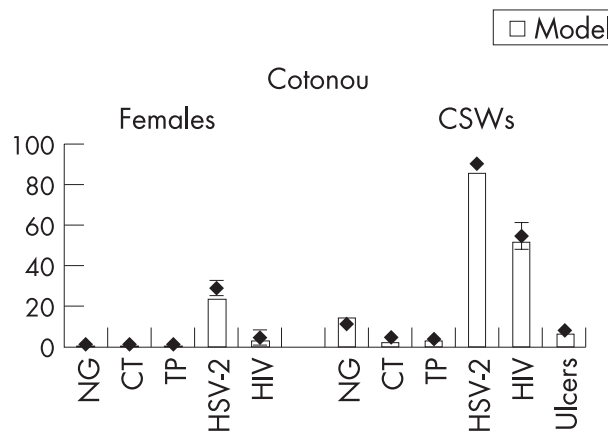

- Data
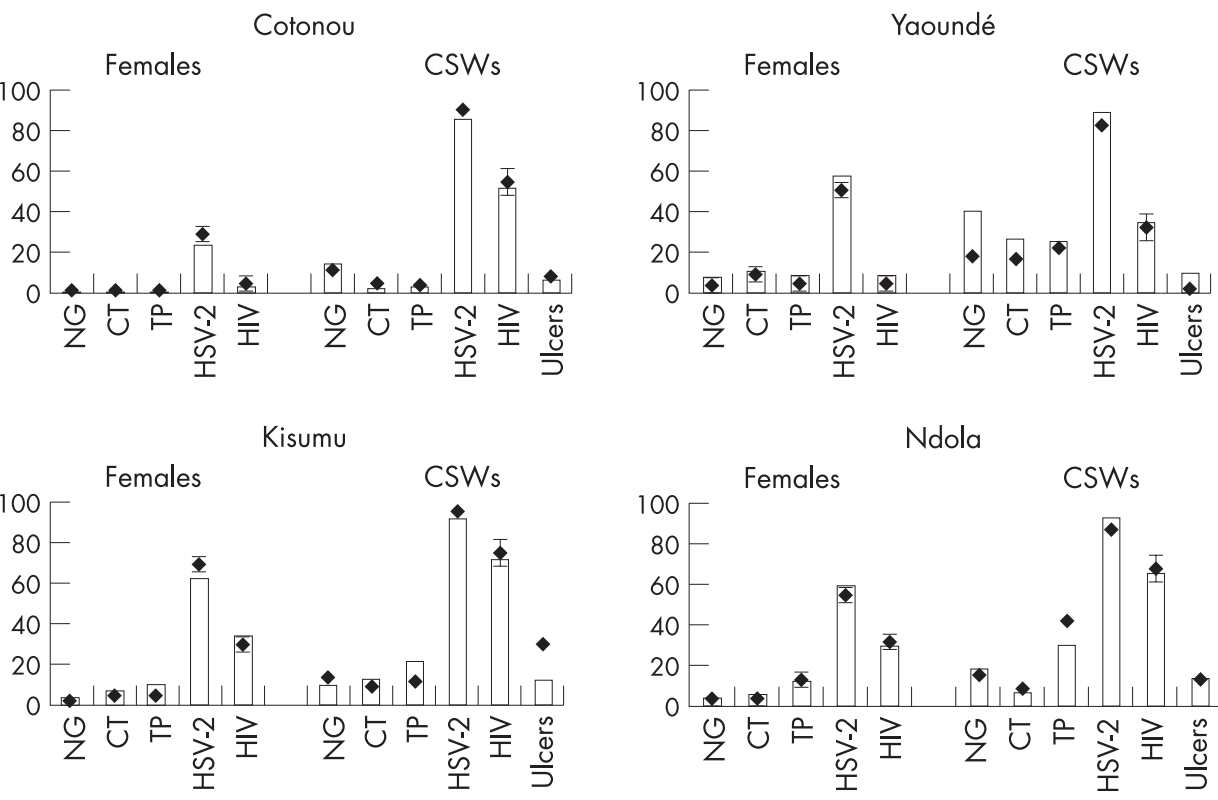

Figure 4 Observed (mean, 95\% Cl where available) and simulated prevalence of sexually transmitted infection (STI) among females in general population and among commercial sex workers (CSWs) in four African cities in 1997. NG, gonorrhoea; CT, chlamydia; TP, syphilis.

study with the highest rates of partner change in Yaoundé and younger ages of sexual debut and marriage in the east African sites, as observed during the study. ${ }^{5}$

A reasonable fit of the model to the demographic, sexual behaviour and epidemiological characteristics of the populations was achieved holding the biological parameters for the natural history and transmission of infection constant across all four sites. The cofactor effects for STIs and male circumcision were also held constant across the sites. The cofactor effect for male circumcision was based on the available data that indicate that male susceptibility to HIV, chancroid and syphilis is doubled in uncircumcised males. ${ }^{43-45}$ The sensitivity analysis suggested that the primary effect of male circumcision during the growth phase of the HIV epidemics in these four cities may have been an indirect effect due to its impact on the prevalence of ulcerative STIs (table 4). A recent randomised controlled trial of male circumcision in South Africa showed male circumcision was strongly protective for HIV acquisition. ${ }^{60}$ Further analysis of the data from the South African trial and the results of the ongoing male circumcision trials in Kenya and Uganda may help distinguish between these direct and indirect effects. Although, in this study, the impact of male circumcision on the development of the contrasting epidemics in east and west Africa may have been mediated by the historical prevalence of chancroid in these populations, this study does not indicate the impact that male circumcision may have on new infections at the present stage of the epidemics in east Africa. This will be addressed in future work.

Although the model was successfully fitted to the data from all four cities, several limitations of our method and the model fits should be highlighted. We were not able to fit every sexual behaviour output to the defined a priori ranges. This may have occurred because our a priori ranges were incorrect despite extensive analyses to define the a priori ranges, including an
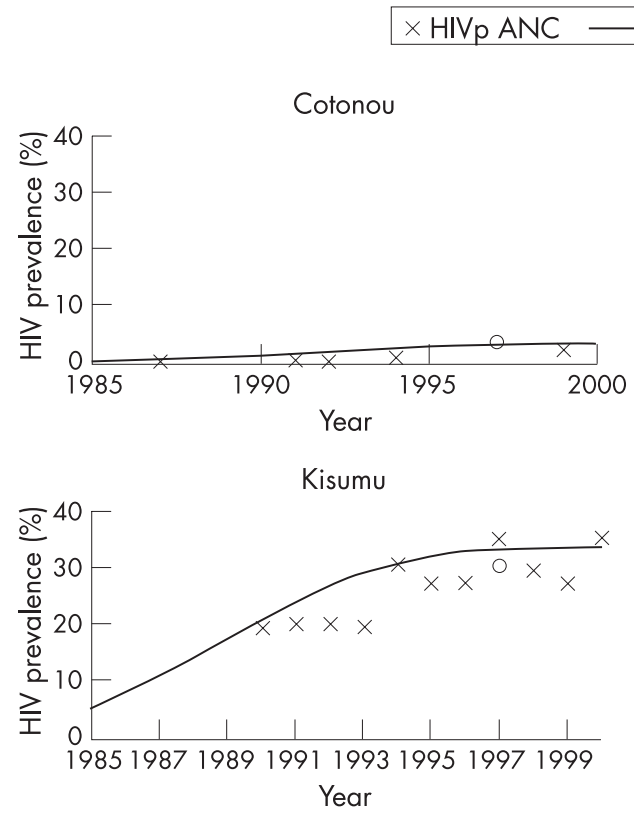

Figure 5 Observed and simulated female HIV prevalence over time for the four cities. ANC, antenatal surveillance data; circles, observed female HIV prevalence from the Four Cities Study.
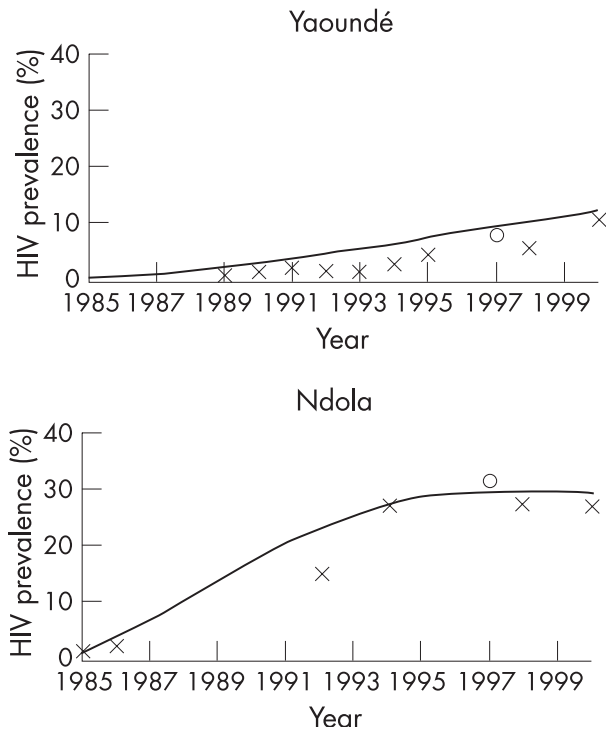
Table 5 Sensitivity analysis model scenarios of simulated HIV and sexually transmitted infection (STI) prevalence in Cotonou and Ndola in 1997 for selected model parameters

\begin{tabular}{|c|c|c|c|c|c|c|c|c|c|c|c|c|}
\hline \multirow[b]{2}{*}{ Parameter } & \multicolumn{6}{|l|}{ Cotonou } & \multicolumn{6}{|l|}{ Ndola } \\
\hline & HIVp F & HIVp CSW & V NGp F & $\begin{array}{l}\text { NGp } \\
\text { CSW }\end{array}$ & HDp F & HDp CSW & HIVp F & $\begin{array}{l}\text { HIVp } \\
\text { CSW }\end{array}$ & NGp F & $\begin{array}{l}\text { NGp } \\
\text { CSW }\end{array}$ & HDp F & $\begin{array}{l}\text { HDp } \\
\text { CSW }\end{array}$ \\
\hline Data & 3.4 & 55 & 0.9 & 12 & NA & NA & 31.9 & 69 & 2.3 & 15 & NA & NA \\
\hline Default model projection & 3.1 & 51.5 & 0.4 & 14.0 & 0.0 & 0.0 & 29.7 & 65.4 & 3.8 & 17.9 & 0.1 & 0.3 \\
\hline \multicolumn{13}{|l|}{ STI cofactors } \\
\hline$\uparrow$ & 10.6 & 84.3 & 0.3 & 12.1 & 0.0 & 0.0 & 50.9 & 92.4 & 3.6 & 18.3 & 0.0 & 0.3 \\
\hline$\downarrow$ & 0.6 & 14.6 & 0.4 & 13.4 & 0.0 & 0.0 & 9.5 & 39.0 & 4.4 & 19.5 & 0.1 & 0.5 \\
\hline \multicolumn{13}{|l|}{ Ulcerative cofactors } \\
\hline$\uparrow$ & 5.3 & 71.0 & 0.4 & 11.4 & 0.0 & 0.0 & 44.6 & 83.4 & 3.6 & 18.0 & 0.0 & 0.3 \\
\hline & 1.8 & 37.0 & 0.4 & 13.7 & 0.0 & 0.0 & 11.9 & 45.5 & 4.3 & 19.5 & 0.1 & 0.3 \\
\hline \multicolumn{13}{|c|}{ Lack of circulating cofactor HIV (default $=2$ ) } \\
\hline$\uparrow=4$ & - & - & _- & _- & - & - & 31.5 & 68.4 & 3.9 & 18.2 & 0.1 & 0.3 \\
\hline$\downarrow=1.5$ & - & - & - & - & - & - & 29.5 & 66.4 & 3.9 & 18.5 & 0.0 & 0.2 \\
\hline \multicolumn{13}{|c|}{ Lack of circulating cofactor all (default $=2$ ) } \\
\hline$\uparrow=4$ & - & - & - & - & - & - & 41.0 & 81.7 & 2.9 & 15.5 & 0.8 & 5.7 \\
\hline$=1.5$ & _- & _- & _- & _- & - & - & 26.9 & 61.9 & 4.2 & 19.9 & 0.0 & 0.1 \\
\hline \multicolumn{13}{|c|}{ Condom use general population* } \\
\hline$\uparrow$ & 2.5 & 44.5 & 0.1 & 4.3 & 0.0 & 0.0 & 25.0 & 58.3 & 1.4 & 5.9 & 0.0 & 0.0 \\
\hline$\downarrow$ & 3.4 & 57.1 & 0.6 & 18.7 & 0.0 & 0.0 & 32.2 & 69.2 & 7.0 & 28.2 & 0.1 & 0.8 \\
\hline \multicolumn{13}{|l|}{ Condom use CSWs } \\
\hline$\uparrow$ & 2.7 & 41.9 & 0.1 & 1.1 & 0.0 & 0.0 & 28.1 & 58.9 & 2.4 & 6.6 & 0.0 & 0.0 \\
\hline$\downarrow$ & 3.3 & 60.6 & 1.0 & 37.9 & 0.0 & 0.0 & 30.0 & 67.1 & 4.6 & 24.7 & 0.1 & 0.7 \\
\hline $\begin{array}{l}\text { CSW screening frequency } \\
\downarrow=6 \mathrm{~m}\end{array}$ & 3.1 & 54.3 & 0.9 & 36.5 & 0.0 & 0.0 & 29.9 & 67.9 & 5.0 & 41.8 & 0.1 & 1.2 \\
\hline \multicolumn{13}{|l|}{$\begin{array}{l}\downarrow=0 \mathrm{~m} \\
\text { CSW treatment coverage } \neq\end{array}$} \\
\hline$\uparrow$ & 3.0 & 51.2 & 0.2 & 5.2 & 0.0 & 0.0 & 29.3 & 64.8 & 3.1 & 6.5 & 0.0 & 0.1 \\
\hline$\downarrow$ & 3.1 & 52.5 & 0.6 & 23.2 & 0.0 & 0.0 & 29.7 & 66.1 & 4.6 & 30.8 & 0.1 & 0.6 \\
\hline Probability of no sex HD 0 & 2.9 & 50.2 & 0.5 & 16.1 & 0.0 & 0.0 & 46.2 & 82.1 & 3.7 & 19.7 & 0.7 & 3.9 \\
\hline $\mathrm{HDp} \uparrow$ & 4.1 & 55.2 & 0.4 & 13.5 & 0.0 & 0.0 & 57.6 & 92.2 & 3.5 & 18.7 & 2.1 & 12.8 \\
\hline
\end{tabular}

$\uparrow$ Represents doubling default value and $\downarrow$ represents halving default value unless otherwise noted.

CSW, commercial sex worker; F, female; HIVp, HIV prevalence; HDp, chancroid prevalence; NGp, gonorrhoea prevalence.

${ }^{*}$ High Cotonou $=20 \%$ (1990), 40\% (1995); low Cotonou and Ndola =5\% (1990), 10\% (1995), high Ndola = 20\% (1990), 50\% (1995).

†High Cotonou $=20 \%$ (1990), 40\% (1993), 80\% (1995); low Cotonou =5\% (1990), 10\% (1993), 20\% (1995); high Ndola =20\% (1990), 50\% (1993), 70\% (1995); low Ndola $=5 \%(1990), 10 \%(1993), 15 \%(1995)$.

$\neq$ High Cotonou $=20 \%$ (1993), $60 \%$ (1995); low Cotonou =5\% (1993), 20\% (1995); low Ndola = 20\% (1993), 50\% (1995); low Ndola =5\% (1993), 10\% (1995).

TProbability of abstaining from sex for males with chancroid, default $=50 \%$.

assessment of time trends in sexual risk behaviour and HIV/STI epidemiology and characteristics of CSWs and their clients. For example, in table 3 we indicated the proportion of males who visit CSWs should be lower in Kisumu than in Cotonou. However, in the process of fitting the HIV/STI epidemiology for the general population and CSWs, the best fit was achieved if these proportions were similar for Kisumu and Cotonou

\section{Key messages}

- The model fit assumed the patterns of sexual behaviour were as observed during the study with the highest partner change rates in Yaoundé and younger ages of sexual debut and marriage in the east African sites.

- By simulating observed patterns in sexual behaviour, STls and male circumcision in the four cities, the model replicated the low HIV prevalence observed in west Africa and high HIV prevalence in east Africa.

- The impact of lack of male circumcision during the growth phase of the HIV epidemics in these four cities may have been an indirect effect due to its impact on the prevalence of ulcerative STIs.

- Varying rates of male circumcision may have played a major role in explaining the strikingly different HIV epidemics observed in different parts of sub-Saharan Africa. (table 4). In this instance, the epidemiological data were deemed to be more reliable than the behavioural data because the reference data ${ }^{48-50}{ }^{55}$ used to help define the a priori ranges may not have been generalisable to the Four Cities Study populations. This illustrates that in some cases, where the behavioural data were scanty, we preferentially fitted the epidemiological data instead of the sexual behaviour data because measures of infection prevalence are not subject to the same uncertainty and biases as reported sexual behaviour.

In addition, although the model seems to fit the data well, it is possible that there are unmeasured but important aspects of the underlying sexual networks that are not adequately represented by this simulation model. Due to the structure of the STDSIM model we do not have precise control over some of the behavioural outputs. For example, a supply and demand mechanism controls commercial sex in the model so the size of the core group cannot be specifically defined by the user even though these data could be estimated from the study. Further modelling studies, focused on the interaction between the sexual network structure, STIs and circumcision cofactor effects on HIV spread, will be helpful. Other important structural constraints of the model include that cofactor effects did not combine in these simulations: if multiple cofactors were present (either multiple STIs or an STI and lack of male circumcision), only the highest cofactor effect was applied. This assumption may overestimate the impact on HIV transmission of biological cofactors with the largest cofactor effects (chancroid and primary HSV-2). The combination of cofactor effects will be explored further to assess how this assumption may affect our findings. 
The sensitivity analysis indicates our model fits depend heavily on the model assumptions for chancroid. First, chancroid was associated with a high HIV cofactor effect ${ }^{25}$ in the model. However, our estimate is at the low end of the range (10-300) reported in the literature. ${ }^{61}$ Second, we assumed male susceptibility to chancroid was doubled in uncircumcised males. Although the magnitude of this effect is not precisely known, the assumption that uncircumcised males are more susceptible to chancroid is consistent with available data. ${ }^{28} 2943$ In the simulations as reported here, the historical prevalence of chancroid was extremely low in west Africa $(0 \%$ in Cotonou and $0.3 \%$ in Yaoundé in 1980 prior to the introduction of HIV), because high rates of male circumcision controlled the spread of chancroid. On the other hand, the simulated prevalence of chancroid was $3.7 \%$ in 1980 in Kisumu and Ndola. This simulated prevalence subsequently drops rapidly due to the introduction of condom use and STI treatment such that at the time of the study the simulated chancroid prevalence was $0 \%$ in Kisumu and $0.1 \%$ in Ndola. This dynamic is consistent with the principle that chancroid is easily controlled with even modest STI treatment as included in our simulations. ${ }^{29}$ Alhough there are no empirical data with which to compare our model estimates for chancroid prevalence, chancroid is known to have been more prevalent in southern Africa in the past. ${ }^{29}$ Hence, our simulations suggest the much less severe epidemics observed in west Africa may be due in part to the protective effect of male circumcision on ulcerative STI, which may have inhibited the initial establishment of HIV in these circumcised populations.

The model scenarios included in the sensitivity analysis suggest the possible role of circumcision in HIV prevention may be linked to the prevalence of other curable STI such as chancroid. If this is indeed the case, the effectiveness of male circumcision as an intervention to prevent HIV incidence may depend on the stage of the HIV epidemic as has been found to be the case for STI treatment interventions. ${ }^{59}$ The protective effect of male circumcision early in an HIV epidemic may occur indirectly through the prevention of ulcerative STI but later in an epidemic, when HIV is more widespread and the prevalence of ulcerative STIs is less, the direct protective effect against HIV acquisition may be more important. In clinical trials of the effect of circumcision on HIV acquisition, it would therefore be important to determine the direct protection circumcision confers against HIV acquisition and that conferred through other STIs such as chancroid.

The contrasting HIV epidemics of east and west Africa were replicated in our model primarily because of the differing prevalences of male circumcision in the four sites. Our preliminary conclusion is therefore that different rates of male circumcision in the four cities may have had an important role in these very different epidemics, and may also help to explain the striking variations in the HIV epidemics in different parts of sub-Saharan Africa. Our model fit will be used to gain further insight into the development and current state of the differing epidemics in east and west Africa as well as the projected impact of potential interventions. In the companion paper in this supplement, we explore the role of different STIs in HIV spread over time across the sites and the results for HSV-2 prevalence are discussed in detail.

\section{ACKNOWLEDGEMENTS}

We thank the Study Group on the Heterogeneity of HIV epidemics in African Cities for cooperation and assistance in carrying out this study.

\section{AUTHOR CONTRIBUTIONS}

$\mathrm{KO}, \mathrm{JG}, \mathrm{RH}, \mathrm{RW}, \mathrm{AB}$, and MCB designed the study. KO and EF designed and conducted the simulations and data analyses. RB and JDF designed and developed STDSIM. All authors contributed to the interpretation of the results and the writing of the manuscript.

\section{Authors' affiliations}

Kate K Orroth, Esther E Freeman, Judith R Glynn, Richard G White,

Richard J Hayes, London School of Hygiene and Tropical Medicine,

London, UK

Roel Bakker, J Dik F Habbema, Erasmus University Rotterdam, Rotterdam, the Netherlands

Anne Buvé, Institute of Tropical Medicine, Antwerp, Belgium

Marie-Claude Boily, Imperial College, London, UK

This study was funded by the Wellcome Trust, Grant No. 069509/Z/02/Z.

Competing interests: None.

\section{REFERENCES}

1 Buve A, Carael M, Hayes RJ, et al. Multicentre study on factors determining differences in rate of spread of HIV in sub-Saharan Africa: methods and prevalence of HIV infection. AIDS 2001;15(Suppl 4):S5-14.

2 Auvert B, Buve A, Lagarde E, et al. Male circumcision and HIV infection in four cities in sub-Saharan Africa. AIDS 2001;15(Suppl 4):S31-40.

3 Weiss HA, Buve A, Robinson NJ, et al. The epidemiology of HSV-2 infection and its association with HIV infection in four urban African populations. AIDS 2001;15(Suppl 4):S97-108.

4 Buve A, Carael M, Hayes RJ, et al. The multicentre study on factors determining the differential spread of HIV in four African cities: summary and conclusions. AIDS 2001;15(Suppl 4):S127-31.

5 Ferry B, Carael M, Buve A, et al. Comparison of key parameters of sexual behaviour in four African urban populations with different levels of HIV infection. AIDS 2001;15(Suppl 4):S41-50.

6 Morison L, Weiss HA, Buve A, et al. Commercial sex and the spread of HIV in four cities in sub-Saharan Africa. AIDS 2001;15(Suppl 4):S61-9.

7 Anon. Zambia Demographic and Health Survey 2001-2002. Calverton, MD: Central Statistical Office, Central Board of Health, ORC, 2003.

8 Nicaise K, Mboup G, Tossou J, et al. Enquete Demographique et de Sante, Republique de Benin 1996. Calverton, MD: Institut National de la Statistique et de l'Analyse Economique et Macro International Inc, 1997.

9 Anon. Enquete Demographique et de Sante au Benin 2001. Calverton, MD: Institut National de la Statistique et de l'Analyse Economique (INSAE) et ORC Macro International, 2002.

10 Balepa M, Fotso M, Barrere B. Enquete Demographique et de Sante Cameroun 1991. Yaoundé, Cameroun: Direction Nationale due Deuxieme Recensement General de la Population et de l'Habitat et Macro, 1992.

11 Fotso M, Ndonou R, Libite PR, et al. Enquete Demographique et de Sante, Cameroun 1998. Calverton, MD: Bureau Central des Recensement et des Etudes de Population et Macro International, 1999.

12 Anon. Kenya Demographic and Health Survey 1989. Nairobi, Kenya: National Council for Population and Development, Ministry of Home Affairs, National Heritage, Institute for Resource Development, Macro Systems, 1989.

13 Anon. Kenya Demographic and Health Survey 1993. Nairobi, Kenya and Calverton, MD: National Council for Population and Development, Central Bureau of Statistics, Office of the Vice President and Ministry of Planning and National Development, Macro International, 1994.

14 Anon. Kenya Demographic and Health Survey 1998. Nairobi, Kenya: National Council for Population and Development, Central Bureau of Statistics, Development Office of the Vice President and Ministry of Planning and National Development, Macro International, Calverton, MD, 1999.

15 Gaisie K, Cross AE, Nsemukila G. Zambia Demographic and Health Survey 1992. Lusaka, Zambia: University of Zambia, Central Statistics Office, Macro International, 1993.

16 Anon. Zambia Demographic and Health Survey 1996. Lusaka, Zambia: Central Statistical Office, Ministry of Health, Macro International, 1997.

17 US Census Bureau. International Database http://www.census.gov/ipc/www/ hitcf.html (accessed January 2004).

18 Korenromp E, Vliet Cv, Bakker R, et al. HIV spread and partnership reduction for different patterns of sexual behaviour: a study with the microsimulation model STDSIM. Math Popul Studies 2000;8:135-73.

19 White RG, Orroth KK, Korenromp EL, et al. Can population differences explain the contrasting results of the Mwanza, Rakai and Masaka HIV/STD intervention trials? A modelling study. J Acquir Immune Defic Syndr 2004;37:1500-3.

20 Morgan D, Mahe C, Mayanja B, et al. Progression to symptomatic disease in people infected with HIV-1 in rural Uganda: prospective cohort study. BMJ 2002;324:193-7

21 Wawer MJ, Serwadda D, Li C, et al. HIV-1 transmission per coital act, by stage of HIV infection in the HIV+ index partner, in discordant couples, Rakai, Uganda. Presented at the 10th Conference on Retroviruses and Opportunistic Infections, Boston, 2003

22 Schacker T, Zeh J, Hu H, et al. Frequency of symptomatic and asymptomatic herpes simplex virus type 2 reactivation among human immunodeficiency virus infected men. J Infect Dis 1998;178:1616-22.

23 Corey L, Wald A, Celum CL, et al. The effects of herpes simplex virus-2 on HIV-1 acquisition and transmission: a review of two overlapping epidemics. AIDS 2004;35:435-45

24 Wawer MJ, Gray RH, Sewankambo NK, et al. Rates of HIV-1 transmission per coital act, by stage of HIV-1 infection, in Rakai, Uganda. J Infect Dis 2005;191:1403-9.

25 Baggaley RF, Boily M-C, White RG, et al. Systematic review of HIV- 1 transmission probabilities: in absence of antiretroviral therapy, Report No.72. 
Geneva: UNAIDS Reference Group on Estimates, Modelling and Projection, 2004.

26 Hanschell HM. Sulphanilamide in the treatment of chancroid. Lancet 1938;i:886-8.

27 Rauschkolb JE. Circumcision in treatment of chancroidal lesions of male genitalia. Arch Dermotal Syph 1939:39:319-28.

28 Ronald AR, Albritton W. Chancroid and Haemophilus ducreyi. In: Holmes KK, Sparling PF, Mardh P, et al, eds. Sexually Transmitted Diseases, 3rd edn. New York: McGraw-Hill, 1999:515-23.

29 Steen R. Eradicating chancroid. Bull WHO 2001;79:818-26.

30 Sparling PF. Natural history of syphilis. In: Holmes KK, Sparling PF, Mardh P, et al, eds. Sexually Transmitted Diseases, 3rd edn. New York: McGraw-Hill, 1999:473-8.

31 DiCarlo RP, Martin DH. The clinical diagnosis of genital ulcer disease in men [see comments]. Clin Infect Dis 1997;25:292-8

32 Corey L, Adams HG, Borwn ZA, et al. Genital herpes simplex virus infections: clinical manifestations, course and complications. Ann Intern Med 1983;98:958-72

33 Koelle DM, Benedetti J, Langeberg A, et al. Asymptomatic reactivation of herpes simplex virus in women after the first episode of genital herpes. Ann Intern Med 1992; 1 16:433-7.

34 Benedetti JK, Zeh J, Corey L. Clinical reactivation of genital herpes simplex virus infection decreases in frequency over time. Ann Intern Med 1999;131:14-20.

35 Obasi A, Mosha F, Quigley M, et al. Antibody to HSV-2 as a marker of sexual risk behaviour in rural Mwanza. J Infect Dis 1999;179:16-24.

36 Wald A, Corey L, Cone R, et al. Frequent genital herpes simplex virus 2 shedding in immunocompetent women. Effect of acyclovir treatment. J Clin Invest 1997;99:1092-7.

37 Wald A, Zeh J, Selke S, et al. Virologic characteristics of subclinical and symptomatic genital herpes infections. N Engl J Med 1995;333:770-5.

38 Paxton LA, Sewankambo N, Gray R, et al. Asymptomatic non-ulcerative genital tract infections in a rural Ugandan population. Sex Transm Inf 1998;74:421-5.

39 Korenromp EL, Sudaryo MK, de Vlas SJ, et al. What proportion of episodes of gonorrhoea and chlamydia becomes symptomatic? Int J STD AIDS 2002;13:91-101.

40 Bailey R, Duong T, Carpenter R, et al. The duration of human ocular Chlamydia trachomatis infection is age dependent. Epidemiol Infect 1999;123:479-86.

41 Korenromp EL, de Vlas SJ, Nagelkerke NJD, et al. Estimating the magnitude of STD cofactor effects on HIV transmission: how well can it be done? Sex Transm Dis 2001;28:613-21.

42 Boily M-C, Anderson RM. Human immunodeficiency virus transmission and the role of other sexually transmitted diseases: Measures of association and study design. Sex Transm Dis 1996;23:312-32.

43 Weiss $\mathbf{H}$, Thomas SL, Munabi S, et al. Male circumcision and sexually transmitted ulcerative infections: a systematic review and meta-analysis. Sex Transm Inf 2006;82:101-10

44 Weiss HA, Quigley MA, Hayes RJ. Male circumcision and risk of HIV infection in sub-Saharan Africa: a systematic review and meta-analysis. AIDS 2000;14:2361-70
45 Baeten JM, Richardson BA, Lavreys L, et al. Female-to-male infectivity of HIV-1 among circumcised and uncircumcised Kenyan men. J Infect Dis 2005:191:546-53.

46 Lydie N, Robinson NJ. Multi-centre study on factors determining the differentia spread of HIV infection in Sub-Saharan Africa: review of demographic indicators in the four study sites. Paris: INSERM, 1996.

47 Lagarde E, Auvert B, Chege J, et al. Condom use and its association with HIV/ sexually transmitted diseases in four urban communities of sub-Saharan Africa. AIDS 2001;15(Suppl 4):S71-8.

48 Voeten HACM, Egesah OB, Ondiege MY, et al. Clients of female sex workers in Nyanza Province, Kenya: a core group in STD/HIV transmission. Sex Transm Dis 2002;29:444-52.

49 Lowndes CM, Alary M, Gnintoungbe CAB, et al. Management of sexually transmitted diseases and HIV prevention in men at high risk: targeting clients and non-paying sexual partners of female sex workers in Benin. AIDS 2000;14:2523-34.

50 Lowndes CM, Alary M, Meda H, et al. Role of core and bridging groups in the transmission dynamics of HIV and STIs in Contonou, Benin, West Africa. Sex Transm Infect 2002;78(Suppl 1):69-77.

51 Carael M, Cleland J, Adeokun L, et al. Overview of selected findings of sexual behaviour surveys. AIDS 1991;5(Suppl):S65-S74.

52 Freeman EE. The role of herpes simplex virus type 2 in the spread and control of HIV in four sub-Saharan African cities. London: University of London, 2006.

53 Asamoah-Odei E, Asiimwe-Okiror G, Boerma T. HIV/AIDS epidemiological surveillance update for the WHO African Region 2002 Country Profiles. Harare, Zimbabwe: World Health Organization, 2003.

54 Anon. HIV/AIDS Surveillance Database. US Bureau of the Census, 2004. http:// www.census.gov/ipc/www/hivaidsd.html.

55 Alary M, Mukenge-Tshibaka L, Bernier F, et al. Decline in the prevalence of HIV and sexually transmitted diseases among female sex workers in Contonou, Benin 1993-1999. AIDS 2002;16:463-70.

56 Joint United Nations Programme on AIDS. Report on the global HIV/AIDS epidemic-2002. Geneva: UNAIDS, 2002

57 Zaba B, Boerma T, White R. Montioring the AIDS epidemic using HIV prevalence data among young women attending antenatal clinics: prospects and problems. AIDS 2000; 14:1633-45.

58 Freeman EE, Orroth KK, White RG, et al. Proportion of new HIV infections attributable to herpes simplex 2 increases over time: simulations of the changing role of sexually transmitted infections in sub-Saharan African HIV epidemics. Sex Transm Infect 2007;83(Suppl 1):i17-i24.

59 Orroth KK, White RG, Korenromp EL, et al. Empirical observations underestimate the proportion of HIV infections attributable to sexually transmitted diseases in the Mwanza and Rakai STD treatment trials: simulation results. Sex Transm Dis 2006;33:536-44.

60 Auvert B, Taljaard D, Lagarde E, et al. Randomized, controlled intervention trial of male circumcision for reduction of HIV infection risk: the ANRS 1265 trial. PLoS Med 2005;2(11)

61 Hayes RJ, Plummer FA. The cofactor effect of genital ulcers on the per-exposure risk of HIV transmission in sub-Saharan Africa. J Trop Med Hyg 1995;98:1-8. 
conflict with UK guidelines. Their preferred regimen for the treatment of pelvic inflammatory disease is in particular surprising (doxycycline and metronidazole) since it conforms with neither UK nor US guidelines and three studies have now shown it to be inferior to alternative regimens.

Overall Fast facts: sexually transmitted infections is to be recommended with just a few caveats.

Jonathan Ross

\section{CORRECTIONS}

doi: 10.1136/sti.2006.021782.corr 1

There was an error in the August issue of the journal (Dodds JP, Johnson AM, Parry JV, et al.
A tale of three cities: persisting high HIV prevalence, risk behaviour and undiagnosed infection in community samples of men who have sex with men. Sex Transm Infect 2007;83:392-6.) The last sentence on page 2 should read as follows: "All were screened by GACELISA HIV 1 and 2, whose sensitivity and specificity had been determined as $99.5 \%$ (95\% CI $97.1 \%$ to $99.9 \%$ ) and $99.7 \%$ (95\% CI $98.9 \%$ to $99.9 \%)$, respectively. ${ }^{13} 14$

doi: 10.1136/sti.2006.023283.corr 1

Several errors occurred in an article published in the July issue of the journal (Evans AR, Wiggins RD, Mercer $\mathrm{CH}$, et al. Men who have sex with men in Great Britain: comparison of a self-selected internet sample with a national probability sample. Sex Transm Infect 2007;83:200-5.) A corrected version of the article is available on our website at http:// sti.bmj.com/supplemental.

doi: 10.1136/sti.2006.023531.corr 1

Two articles from the August 2007 supplement were unlocked online but not in print. The articles are: Orroth KK, Freeman EE, Bakker R, et al. Understanding the differences between contrasting HIV epidemics in east and west Africa: results from a simulation model of the Four Cities Study. Sex Transm Infect 2007;83(Suppl 1):i5-i6 and Freeman EE, Orroth KK, White RG, et al. Proportion of new HIV infections attributable to herpes simplex 2 increases over time: simulations of the changing role of sexually transmitted infections in sub-Saharan African HIV epidemics. Sex Transm Infect 2007;83(Suppl 1):il7-i124. Both articles are freely available. 